Original Article

\title{
In New Geon Extra Peritioneal Caesarean Section An Observational Study
}

\author{
Daise $\mathrm{TA}^{1}$, Ara $\mathrm{BH}^{2}$, Tasnim $\mathrm{S}^{3}$, Ahsan $\mathrm{B}^{4}$, Chowdhury $\mathrm{SR}^{5}$ Imran $\mathrm{S}^{6}$
}

\begin{abstract}
This study was designed to find out the maternal and perinatal outcome among 80 women undergoing extraperitoneal cesarean section.

This observational study was conducted at Institute of Child and Mother Health, Matuail, Dhaka 1st March 2013 to 28th February 2014. Data were collected by structured questionaire ith the writen consent of patients irrespective of routine and emergency cases where the procedure was successful in all patients. During operation, time was taken from open to close, incision to delivery of baby, total amount of blood loss during procedure, intraoperative complications, APGAR score of newborn were documented. Time required for return of bowel sound mobilization of patient within 24 hour and, duration of hospital stay were also included.
\end{abstract}

Success rate of extra peritoneal CS was 100\%, Time taken from incision to delivery was $\leq 6$ minutes in $62.2 \%$ cases, time taken from incision to closure was between 31-45 min in $72.5 \%$ cases, blood loss $\leq 500 \mathrm{ml}$ in $62 \%$ cases, return of bowel function between 5-8 hours in 52.5\%, mobilization within 24 hours in 52.5\%, neonatal one minute APGAR score $\geq 7$ in $93.91 \%$.

Conclusions: As a surgical form of infection prophylaxis extraperitoneal cesarean section can be applied to avoid serious post-operative pelvic infections and its complications

1. Dr. Tahmina Afreen Daise, Associate Professor, Gynae \& Obst. ICMH, Matuail, Dhaka-1362

2. Prof. Begum Hosne Ara, Executive Director \& Professor Head Obgyn, ICMH, Matuail, Dhaka-1362

3. Prof. Saria Tasnim, Professor of Gynae \& Obst., Ex. Executive Director, ICMH, Matuail, Dhaka-1362,

4. Dr. A.K.M Badrul Ahsan, Chest Disease Specialist, Deputy Director, IFA

5. Dr. Sushmita Ray Chowdhury, Emergency, Medical Officer, ICMH, Matuail, Dhaka

6. Dr. Shahed Imran, Registrar, (Ped Surgery) ICMH, Matuail, Dhaka

${ }^{*}$ For correspondence
Extraperitoneal cesarean section would be a rational practice of cesarean section in the modern era.

Key words: Extraperitoneal, Caesarean section, Transperitoneal.

\section{INTRODUCTION}

Due to caesarean section maternal mortality has been reduced drastically. Maternal morbidity like post operative pain, infection and post operative adhesions still present. Soiling of the peritoneal cavity may occur by infected amniotic fluid from the uterus, blood and handling of bowel which mainly result maternal mortality.

When the peritoneal cavity is opened by transperitoneal approach, organisms enters into the peritoneal cavity not only from skin and fascia but also from amniotic fluid especially when infected. Moreover, peritoneal cavity and intestines are subjected to dryness, and, chemical and physical injury by packs and tetra. As a results it is associated with paralytic ileus, wound sepsis, peritonitis and septicemia. All this occur especially in cases of prelabour rupture of membrane, prolonged labour. As a result there is prolonged hospital stay. ${ }^{1,2}$

To reduce the morbidity and higher mortality of classical trans-peritoneal caesarean section in the pre-antibiotic era, the extraperitoneal approach was devised. It was first performed by Ferdinand Ritgen (1787-1867) of Gissen in 1821. ${ }^{3}$ The procedure was further modified by Latzko, Waters and Norton. This extraperitoneal approach reduced the mortality and morbidity to a significant extent. ${ }^{4}$

\section{MATERIALS AND METHODS}

This observational study was conducted in Institute of Child and Mother Health, Matuail, Dhaka. Data was collected by structured data sheet from $1^{\text {st }}$ April 2013 to $28^{\text {th }}$ March 2014.

Inclusion criteria: Elective and emergency extraperitoneal all cases of caesarean section.

Exclusion criteria :

i. Placenta praevia

ii. Previous abdominal surgeries

iii. Prior surgeries on bladder

iv. Women requiring caesarean section with bilateral tubal ligation 
Operative technique : Spinal anesthesia or general anesthesia were given to the patients as indicated. Catheterization of the bladder was done before operation. Skin incision was given either transverse supra-pubic or longitudinal. Transversally rectus sheath was incised and rectus muscles were separated. Transversals fascia was separated after separation of the recti. Urinary bladder covering the lower uterine segment was exposed.

By bilateral paravesical dissection, the peritoneal attachment to the dome of the bladder was isolated and by blunt dissection peritoneal fold was separated and was pushed upward to expose the lower uterine segment. Transverse incision was given to uterus and baby was deliver. After delivery of placenta and membrane, uterus was closed with number one chromic catgut in single layer.

Proper haemostasis was done. After ensuring no bladder injury and confirming the instrument and mop count, rectus muscles were approximated and rectus sheath was closed with $1 / 0$ vicryl and skin closure was done subcutaneously by $2 / 0$ vicryl.

Pre-operative antibiotic (Inj. $1 \mathrm{gm}$ ceftriaxone) given to all patients before starting the procedure. In the post-operative word, patient's pulse, blood pressure, temperature, per vaginal bleeding were recorded daily. By mouth was given after appearance of bowel sounds. Four hour after operation patients were encouraged for early ambulation. Routine injectable antibiotics and analgesics were given for 24 hours. Catheter removal was done routinely after 24 hours, except in cases of obstructed labor.

Post-operative complications as pyrexia, pain, abdominal distention, wound infection, etc were taken into consideration and details reported. Post-operative pain was assessed using the visual analogue scale of 0 to 10 where ' 0 ' represents 'no pain' and '10' represents 'worst pain ever experienced'. Patients were discharged on third post-operative day if no other complication.

\section{RESULTS}

In the present study of 80 cases of extraperitoneal cesarean section. Analysis was done meticulously considering a wide range of parameters.

The maximum number of women belonged to the age group $18-26$ years $(73 \%)$. Most of the women in our study were primigravida $(92 \%), 6 \%$ were second gravida and $2 \%$ third gravida. $89 \%$ of the women were term at delivery, $9 \%$ were preterm and $2 \%$ were post term. $95 \%$ of cases had a cephalic presentation, followed by breech (4\%) and transverse lie (1\%). Majority of patients had ruptured membranes at admission (76\%).

The most common indication for cesarean section was fetal distress (37\%), followed by CPD (24\%), oligohydramnios $(14 \%)$, fetal growth restriction $(11 \%)$, breech presentation $(4 \%)$, transverse lie $(1 \%)$, post term $(3 \%)$ and DTA $(3 \%)$. $3 \%$ of cases constituted other causes.

Of the 80 cases in which extraperitoneal cesarean section was tried, procedure was successful in 80 cases (100\%).

Table 1: Success rate of extraperitoneal CS.

\begin{tabular}{|l|c|c|}
\hline & No. of cases & Percentage (\%) \\
\hline Cases tried & 80 & 100 \\
\hline Success & 80 & 100 \\
\hline
\end{tabular}

The time taken from skin incision to baby delivery was $\leq 6$ minutes in $62.2 \%$ of the cases. In $4 \%$ of the cases, the incision-delivery interval was $>10$ minutes (Table 2). The duration of the surgery from skin incision to closure was between $31-45$ minutes in $72.5 \%$ of the women. The procedure took $>60$ minutes in $3.7 \%$ of cases (Table 3 ).

The total blood loss during the procedure was $\leq 500 \mathrm{ml}$ in $62 \%$ of the cases. Blood loss $>1000 \mathrm{ml}$ was present in $4 \%$ of the cases.

Table 2: Time taken - incision to delivery.

\begin{tabular}{|l|c|c|}
\hline $\begin{array}{l}\text { Incision-delivery } \\
\text { interval (minutes) }\end{array}$ & No. of cases & Percentage (\%) \\
\hline$\leq 6$ & 50 & $62.2 \%$ \\
\hline $6-10$ & 26 & $32.2 \%$ \\
\hline$>10$ & 4 & $5.6 \%$ \\
\hline
\end{tabular}

Table 3: Time taken - incision to closure.

\begin{tabular}{|l|cc|}
\hline $\begin{array}{l}\text { Incision-delivery } \\
\text { interval (minutes) }\end{array}$ & No. of cases & Percentage (\%) \\
\hline$\leq 30$ & 12 & $15.4 \%$ \\
\hline $31-45$ & 58 & $72.5 \%$ \\
\hline $46-60$ & 7 & $8.4 \%$ \\
\hline$>60$ & 3 & $3.7 \%$ \\
\hline
\end{tabular}

Bladder injuries was not occur in this study. Maximum number of patients $(80 \%)$ had pain scores between 0 - 5 . In $16.25 \%$ of the patients, pain scores were $6-7$, and, in 
$3.75 \%$ of patients score was $>8$ (Table 4 ). $80 \%$ of the women did not require any additional analgesics.

Table 4: Post-operative pain.

\begin{tabular}{|l|c|c|}
\hline Pain scores & No. of cases & Percentage (\%) \\
\hline $0-5$ & 64 & $80 \%$ \\
\hline $6-7$ & 13 & $16.25 \%$ \\
\hline$>8$ & 3 & $3.75 \%$ \\
\hline
\end{tabular}

Return of bowel sounds was present between 5-8 hours in $52.5 \%$ of the women. In $40 \%$ of the women, bowel sounds appeared at 4 hours (Table 5). Mobilization of the patient occurred within 24 hours in $52.5 \%$ of the patients, and, between $24-48$ hours in $40 \%$ of the patients (Table 6).

Table 5: Appearance of bowel sounds.

\begin{tabular}{|l|c|c|}
\hline $\begin{array}{l}\text { Appearance of bowel } \\
\text { sounds (hours) }\end{array}$ & No. of cases & Percentage (\%) \\
\hline 4 & 32 & $40 \%$ \\
\hline $5-8$ & 42 & $52.5 \%$ \\
\hline $9-12$ & 6 & $7.5 \%$ \\
\hline$>12$ & - & - \\
\hline
\end{tabular}

Table-6: Mobilization of patient.

\begin{tabular}{|l|c|c|}
\hline $\begin{array}{l}\text { Mobilization of } \\
\text { patient (hours) }\end{array}$ & No. of cases & Percentage (\%) \\
\hline$\leq 24$ & 42 & $52.5 \%$ \\
\hline $24-48$ & 32 & $40 \%$ \\
\hline $48-72$ & 6 & $7.5 \%$ \\
\hline$>72$ & - & - \\
\hline
\end{tabular}

Post operatively, pyrexia was present in $2 \%$ cases, urinary tract infection in $2 \%$ cases. No cases of wound infection, wound gaping, burst abdomen, sub-acute intestinal obstruction, sub-involution, peritonitis and genitor-urinary fistula were present in this study. Duration of hospital stay was $\leq 4$ days in $88 \%$ of cases, $2 \%$ of cases had prolonged hospital stay $>8$ days. $67 \%$ of the babies born by extraperitoneal cesarean section in our study had birth weight between $2.5-3.5 \mathrm{~kg}$. $23 \%$ cases had birth weight $\leq 2.5 \mathrm{~kg}$ and in $10 \%$ cases, babies weighed $>3.5 \mathrm{~kg}$. The neonatal APGAR score was $\geq 7$ in $93.91 \%$ cases. No cases of birth injuries was found in this study.

\section{DISCUSSION}

Caesarean sections which was done due to intra-uterine sepsis and after prolonged labour may cause various complications like wound sepsis, paralytic ileus, peritonitis, septicemia shock and even cause death of patients. Among all complications some of serious complications can be preventable by asepsis and appropriate antibiotics.

With this consideration the resurrecting extraperitoneal caesarean section from obstetric history, in the hope of reducing risks of sepsis associated with caesarean section.

Decrease risk of infectious complications in comparison to the conventional transperitoneal caesarean section, the women undergoing extraperitoneal cesarean section can be advocated. Fluids and feeding earlier in the post-operative period, and also ambulate early thereby reducing hospital stay. Extra peritoneal cesarean section can also ensure early feeding in the post operative period and also early ambulation. So their by reducing hospital stay duration.

If proper precautions are taken, complications like injury to the bladder and blood vessels can be avoided. Bangladesh like developing countries where obstetric sepsis is still a major cause of morbidity and mortality, any procedure that will prevent peritoneal contamination deserves consideration. Decreased infection rate, early mobilization and return of bowel function may weigh over the increased time taken for the procedure and technical difficulty.

\section{REFFERENCES}

1. E. W. Cartwright. Extraperitonal caesarean section: Physick-Sellheim principle. West J Surg. 1949; 57:509.

2. Derk Crichton. A simple technique of extraperitoneal caesarean section. S Afr Med J. 1973; 47:2011.

3. Marshall CM. Extraperitoneal approach. In: Marshall CM, eds. Caesarean Section Lower Segment Operation. 1st ed. Bristol: John Wright; 1939.

4. Nanda SS et al. Int J Reprod Contracept Obstet Gynecol. 2014 Sep;3(3):724-727 